Check for updates

Cite this: RSC Adv., 2017, 7, 27113

\title{
Liquefied walnut shell-derived carbon nanofibrous mats as highly efficient anode materials for lithium ion batteries
}

\author{
Lei Tao, (D) ${ }^{a}$ Yunwu Zheng, ${ }^{\text {ab }}$ Yanhua Zhang, ${ }^{a}$ Huan Ma, ${ }^{\text {bc }}$ Mingwei Di ${ }^{\star a}$ \\ and Zhifeng Zheng*b
}

Mechanically flexible walnut shell-derived carbon nanofibers (CNFs) of $175 \mathrm{~nm}$ diameter were fabricated from a liquefied walnut shell-polyvinyl alcohol (PVA) hybrid solution via conventional electrospinning followed by one-step carbonization. The morphology and structure properties, as well as pore structure properties of walnut shell-derived CNFs were comprehensively characterized by field-emission scanning electron microscopy (FE-SEM), X-ray photoelectron spectroscopy (XPS), Raman spectroscopy, and their electrochemical performances were evaluated for the first time as electrode materials in lithium ion batteries, without addition of any conductive agent or binder. The walnut shell-derived CNFs mats exhibited a high specific capacity above $150 \mathrm{~mA} \mathrm{~h} \mathrm{~g}^{-1}$ with an initial efficiency of $50.4 \%$ at a current density of $100 \mathrm{~mA} \mathrm{~g}^{-1}$ and good cycle stability at different current rates (above 200 and $120 \mathrm{~mA} \mathrm{~h} \mathrm{~g}^{-1}$ at 20 and $1000 \mathrm{~mA} \mathrm{~g}^{-1}$, respectively). After 100 cycles at a current density of $100 \mathrm{~mA} \mathrm{~g}{ }^{-1}$, walnut shellderived CNF mats still maintained a good capacity of about $150 \mathrm{~mA} \mathrm{~h} \mathrm{~g}{ }^{-1}$. This demonstrated the great prospect of walnut shell-derived CNF mats as electrode materials for applications in electrical energy storage.

Received 6th March 2017
Accepted 14th May 2017

DOI: 10.1039/c7ra02716h

rsc.li/rsc-advances resources and various environmental issues, developing "green" and reliable electrode materials that combine high electrochemical performance with low-cost is still a challenge for almost every manufacturer.

Nature provides a variety of renewable resources (such as cellulose ${ }^{\mathbf{1 1}}$ lignin, ${ }^{\mathbf{1 2}}$ chitosan, ${ }^{\mathbf{1 3}}$ peanut shells ${ }^{\mathbf{1 4}}$ and protein, ${ }^{\mathbf{1 5}}$ etc.) that can be demonstrated to be promising candidates as carbon electrode materials for energy applications with obvious low cost and environment benefits. Nevertheless, most of the carbon precursors are not self-supporting, binder-free, and are even manufactured from complicated and cumbersome process.

Electrospinning is a straightforward and powerful method for generating highly porous free-standing carbon nanofibers mats that could be directly used as electrode materials for energy storage devices without adding any conductive agent or binder, which could simplify the fabrication process to a great extent. ${ }^{16-18}$ In recent years, many research results indicated that the carbon fibrous mats made from natural biomass materials-lignin via electrospinning as binder-free electrodes for lithium ion batteries and supercapacitors exhibited high electrochemical performances because of their self-supporting conductive networks. ${ }^{19-21}$ However, the purity of lignin is one of the critical factors to potentially achieve good fiber electrospinnability. ${ }^{22}$ There are a variety of lignins commercially available, depending on the different chemical process and pulping techniques, such as Alcell lignin, Kraft lignin and
${ }^{a}$ College of Materials Science and Engineering, Northeast Forestry University, Harbin 150040, China.E-mail: dimingwei@nefu.edu.cn

${ }^{b}$ Engineering Laboratory for Highly-Efficient Utilization of Biomass, University Key Laboratory for Biomass Chemical Refinery \& Synthesis, College of Materials Engineering, Southwest Forestry University, Kunming 650224, Yunnan Province, China. E-mail: zhengzhifeng666@163.com

${ }^{c}$ Chemistry Department, Colorado School of Mines, Golden 80401, USA 
lignosulfonate which were generated from the Alcell, Kraft and sulfite pulping process, respectively. ${ }^{23}$ However, those lignins contain inorganic or organic impurities like ashes, salts and volatile substances, ${ }^{24}$ which requires a further purification process such as acid, ${ }^{25}$ filter membrane ${ }^{26}$ and organic solvent treatment. ${ }^{27}$ Walnut shell, abandon lignocellulosic resources in the world containing abundant cellulose and lignin, is widely used as a resource for renewable energy and materials. In order to effectively utilize lignocellulosic resources to produce high value-added products, liquefaction technique was used to prepare biomass-based carbon nanofibers in our laboratory. Compared with the purification of refined lignin, liquefaction is a more convenient technique to maximize the utilization of lignocellulosic resources (e.g. walnut shell). Thus, we have strictly focused on converting this abandon lignocellulosic resource to electrospun carbon nanofibers as electrode materials for energy storage devices. Moreover, there have been no reported studies on (1) the preparation of electrospun carbon nanofibrous mats from liquefied walnut shell (2) the resultant walnut shell-derived CNFs mats as binder-free electrode materials for lithium ion batteries.

In this work, we present a straightforward method to manufacture walnut shell-derived carbon nanofibers from liquefied walnut shell via electrospinning followed by one-step carbonization. The morphology and structure of the walnut shell-derived carbon nanofibers were studied, and their electrochemical properties as anode for lithium ion batteries were investigated for the first time. The results demonstrate that the flexible and ultrafine walnut shell-derived CNF mats have a large specific surface area, fast lithium charge/discharge kinetics, and good electrochemical performance as freestanding/binder-free electrodes for applications in lithium ion batteries.

\section{Experimental}

Materials

Walnut shell (Juglans Sigillata Dod) was ground (>100 mesh) and dried in an oven at $80{ }^{\circ} \mathrm{C}$ until a constant weight was obtained, then kept in a desiccator before use. Polyvinyl alcohol (PVA) with molecular weight of $M_{\mathrm{w}}=125000 \mathrm{~g} \mathrm{~mol}^{-1}$ and degree of hydrolysis of $88 \%$ (typical, CAS number: 8068-05-1) was purchased from Sigma-Aldrich. Phenol $\left(\mathrm{C}_{6} \mathrm{H}_{5} \mathrm{OH}\right)$, sulfuric acid $\left(\mathrm{H}_{2} \mathrm{SO}_{4}, 98 \mathrm{wt} \%\right)$, formaldehyde $\left(\mathrm{CH}_{2} \mathrm{O}, 37 \mathrm{wt} \%\right)$, and sodium hydroxide $(\mathrm{NaOH})$ were purchased from Sinopharm Chemical Reagent Co., Ltd., China and were all used as received without further purification.

\section{Preparation of electrospinning solution}

The mixture of walnut shell powder, phenol and sulfuric acid at a mass ratio of $1 / 4 / 0.03$ was liquefied for $2 \mathrm{~h}$ at $150{ }^{\circ} \mathrm{C}$. Afterwards, the mixture was poured into dioxane/water $(8 / 2, v / v)$ at a volume ratio of $1 / 15$. The diluted solution was filtrated and concentrated under reduced pressure to obtained impuritiesfree liquefied products. In the previous work, ${ }^{28}$ the liquefied phenol formaldehyde resin (LPF) was synthesized by formaldehyde (F), liquefied products (LP) with sodium hydroxide $(\mathrm{NaOH})$ as catalyst (molar ratio, $\mathrm{F} / \mathrm{LP}=1.45 / 1, \mathrm{NaOH} /$ $\mathrm{LP}=0.2 / 1$ ). In synthesizing resin (LPF), LP, $\mathrm{NaOH}$ solution and $80 \%$ of the total $\mathrm{F}$ were added into a three-neck flask. The solution was heated to $82{ }^{\circ} \mathrm{C}$ for $60 \mathrm{~min}$. After that, the remaining $20 \%$ of $\mathrm{F}$ was added. Reaction temperature was increased to $87^{\circ} \mathrm{C}$ and kept for $120 \mathrm{~min}$ under stirring, followed by cooling to room temperature. Subsequently, the synthesized LPF was diluted to $18 \mathrm{wt} \%$ in solid content with distilled water and 12 wt\% polyvinyl alcohol (PVA) aqueous solution added into the LPF to adjust the electrospinability (mass ratio of LPF/ PVA $=8 / 2$ ). The mixed solution stirring was continued for $2 \mathrm{~h}$. After all, the electrospinning solution was obtained.

\section{Preparation and characterization of walnut shell-derived carbon nanofibers}

Electrospun nanofibers were manufactured by electrospinning device (ET-2535H, Ucalery, China) which consisted of a high voltage power supply, a syringe pump, and a roller (covered with an aluminium foil) connected to the negative pole for collecting the fibers. The spinning solution was loaded into a $5 \mathrm{~mL}$ plastic syringe with a 22 gauge needle which was connected to the positive pole of a voltage generator. During spinning, the distance was adjusted to $25 \mathrm{~cm}$ between the tip of needle and the roller, an operating voltage was ranged from $16 \mathrm{kV}$ and the feeding rates of spin was maintained at $0.05 \mathrm{~mL} \min ^{-1}$. The carbon nanofibers were fabricated by one-step carbonation at $900{ }^{\circ} \mathrm{C}$ at a rate of $5{ }^{\circ} \mathrm{C} \mathrm{min}^{-1}$ and held for $60 \mathrm{~min}$ in a nitrogen atmosphere.

The morphology of walnut shell-derived carbon nanofiber (CNFs) was characterized using a scanning electron microscopy (SEM, JSM-5600LV). The Raman spectrometer (Raman-Station 400, PerkinElmer, MA, USA) was used to examine the experimental CNFs in terms of graphite structure. Chemical surface composition of the CNFs was determined by X-ray photoelectron spectroscopy (XPS, ESCALAB250Xi, ThermoFisher). The yield of CNFs after carbonization was characterized by thermogravimetric analysis (TGA, NETZSCH). The specific surface area and pore structure of the nanofibers were analyzed by $\mathrm{N}_{2}$ adsorption-desorption isotherms measured at $-196{ }^{\circ} \mathrm{C}$ using an ASAP 2020 Plus HD88 analyzer (Micromeritics Co., Ltd.).

\section{Electrochemical measurement}

The electrochemical performance was tested with the walnut shell-derived carbon fibrous mats, lithium foil, and $1 \mathrm{M} \mathrm{LiPF}_{6}$ in ethylene carbonate/dimethyl carbonate $(1: 1 \mathrm{v} / \mathrm{v}$ ratio) as the working electrode (without addition of any binder and conductive additive), counter electrode, and electrolyte, respectively. The cyclic voltammetry (CV) test was performed on a CHI760E electrochemical workstation (Chenhua Instrument Company, Shanghai, China) at a scan rate of $0.1 \mathrm{mV} \mathrm{s}^{-1}$ between 0 and $3.0 \mathrm{~V}$. The electrochemical impedance spectroscopy (EIS) study was conducted using the same electrochemical work station in a frequency range of $10^{6}$ to $10^{-2} \mathrm{~Hz}$ and at an ac amplitude of $5 \mathrm{mV}$. The galvanostatic charge/ 
discharge experiments were conducted using a multi-channel Land Battery Test System over the range of 0.01-3.0 V.

\section{Results and discussion}

Due to lack of chain structures and/or molecular entanglements of liquefied phenolic resin (LPF), electrospinning of pristine LPF solution at any concentration is challenging and it results in electrospraying of the solution and forming spherical droplets with no fiber collectable (Fig. 1a). ${ }^{29}$ For these reasons, we must added a few amounts of PVA aqueous solution (spinning auxiliary) blend with LPF to improve its fluid properties and electrospinnability. Fig. 1 shows SEM images of as-spun walnut shell-derived nanofibers resulted from LPF/PVA hybrid solutions. As can be clearly seen from Fig. 1b, uniform nanofibers could be readily formed from LPF/PVA mixture solutions, whereas a higher amount of LPF (>90\%) in the solutions resulted in beaded fibers or sprayed particles. At the same time, as-spun nanofibers and resultant carbon nanofibers exhibited long and smooth fibrous morphologies with average diameters decreasing from $\sim 287 \mathrm{~nm}$ to $175 \mathrm{~nm}$ (Fig. 1b-e), which are much smaller and more uniform than that of electrospun other walnut shell-derived nanofibers..$^{19,20}$ Noted that the carbonized membrane still maintains good mechanical flexibility and dimensional stability, and it could be bent without breaking (Fig. 1e), which is demonstrated to be a potential material used in electrical energy storage (Fig. 1f).
The walnut shell-derived CNF surface elemental composition and atomic concentrations were characterized by X-ray photoelectron spectroscopy (XPS) method, as shown in Fig. 2a-c. The two main peaks including $\mathrm{C} 1 \mathrm{~s}$ and $\mathrm{O} 1 \mathrm{~s}$ were seen for the survey spectrum (Fig. 2a), implied that $\mathrm{C}$ and $\mathrm{O}$ were the major component elements of walnut shell-derived CNFs, by which the carbon content was more than $97 \%$. The C 1s spectra ranging from 280 to $296 \mathrm{eV}$ can be subdivided into five obvious peaks ${ }^{30}$ corresponding to the C-C $(284.38 \mathrm{eV}), \mathrm{C}-\mathrm{O}(285.54 \mathrm{eV})$, $\mathrm{C}=\mathrm{O}(286.58 \mathrm{eV}),-\mathrm{COOH}(287.98 \mathrm{eV})$ and $\mathrm{CO}_{3}{ }^{2-}, \mathrm{CO}_{2}, \mathrm{CO}$ $(289.78 \mathrm{eV})$, with the relative percentages of $66.41 \%, 9.94 \%$, $7.00 \%, 6.94 \%$ and $6.74 \%$, respectively, as shown in Fig. $2 \mathrm{~b}$. The $\mathrm{O} 1 \mathrm{~s}$ spectrum can be fitted into two components ${ }^{31}$ centered at $531.5 \mathrm{eV}$ and $532.8 \mathrm{eV}$, which could be assigned to carbonyl oxygen in $\mathrm{COOR}(\mathrm{C}=\mathrm{O}, 2.27 \%)$ and hydroxyl oxygen $(-\mathrm{OH})$ or ether oxygen (C-O-C, $0.70 \%$ ), respectively, as shown in Fig. 2c. The elements' atomic content and the results of the fits of the $\mathrm{C}$ 1s and $O$ 1s region were summarized in Table 1.

Compared with X-ray diffraction (XRD), the Raman spectroscopy is a more sensitive technique for the characterization of various forms of disordered carbons. ${ }^{32}$ Thus, Raman spectroscopy was used as to understand structural changes of walnut shell-derived CNFs during the carbonization process. Fig. $2 \mathrm{~d}$ shows the typical features of carbon materials where two bands are depicted. The strong peak centers at $1340 \mathrm{~cm}^{-1}$ corresponds to the disorder carbon (D) band, which caused by the $\mathrm{A}_{1 \mathrm{~g}}$ mode, while another peak appears at $1590 \mathrm{~cm}^{-1}$
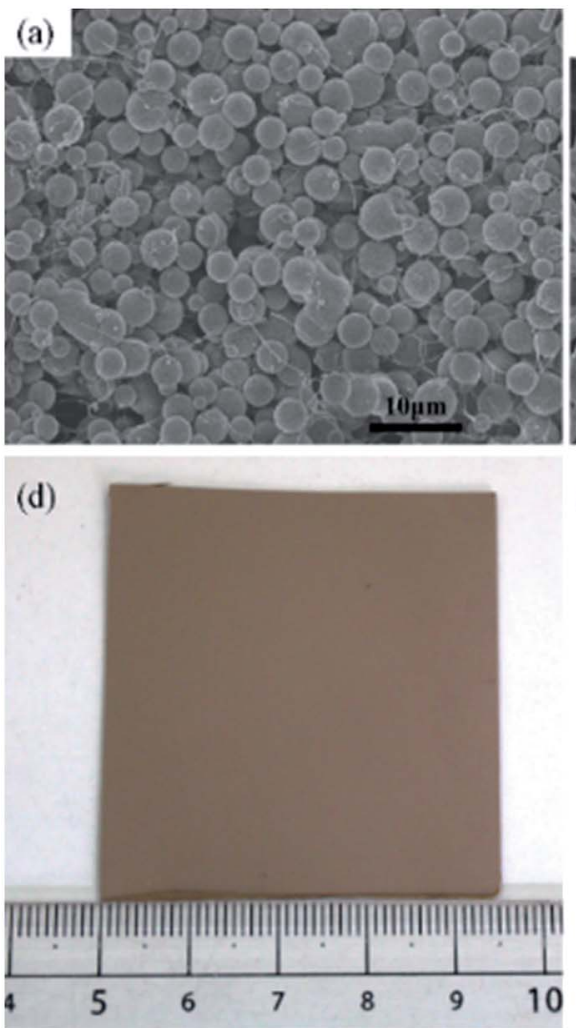

(e)

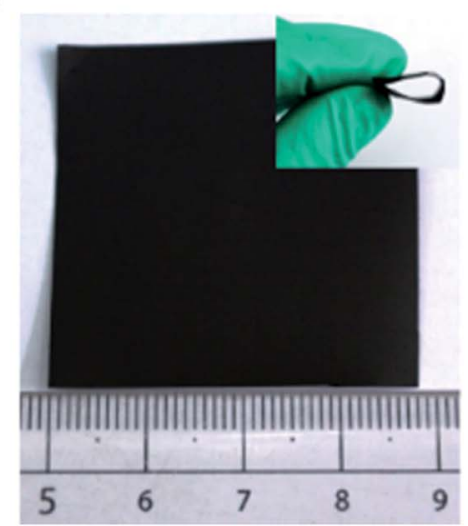

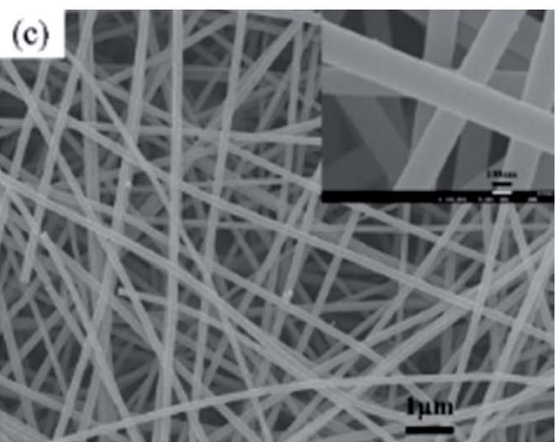

(f)

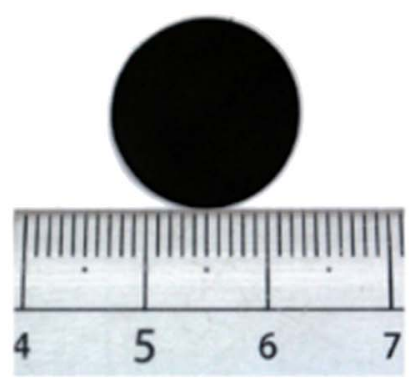

Fig. 1 SEM images of electrospun walnut shell-derived nanofibers with LPF to 12 wt\% PVA ratios of (a) $10: 0 ;$ (b) $8: 2$ and corresponding carbon nanofibers (c), and the photograph of as-spun fibrous mats (d); carbon fibrous mats (e); the electrode of LIBs (f). 
(a)

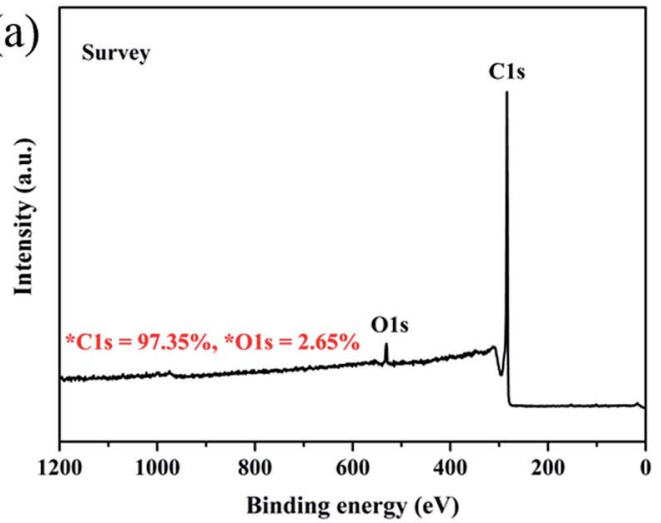

(c)

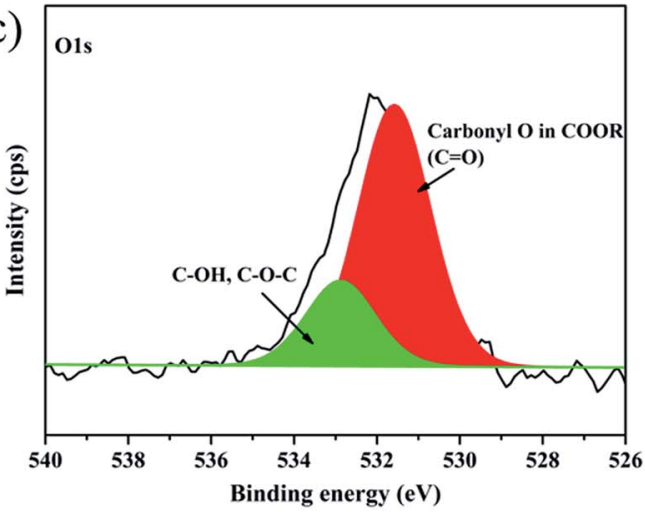

(b)

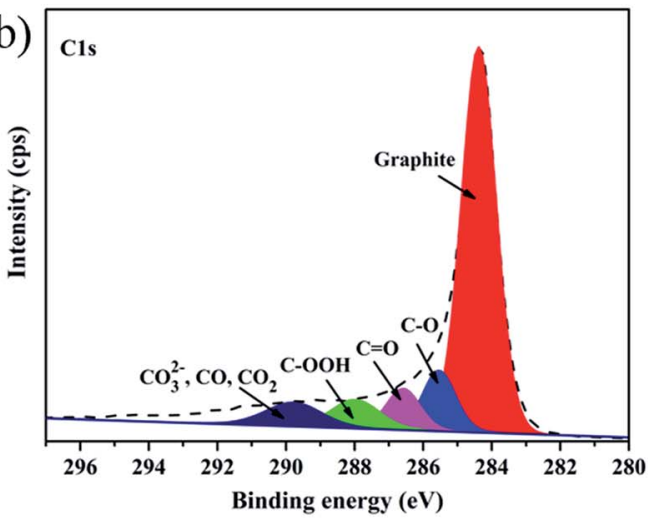

(d)

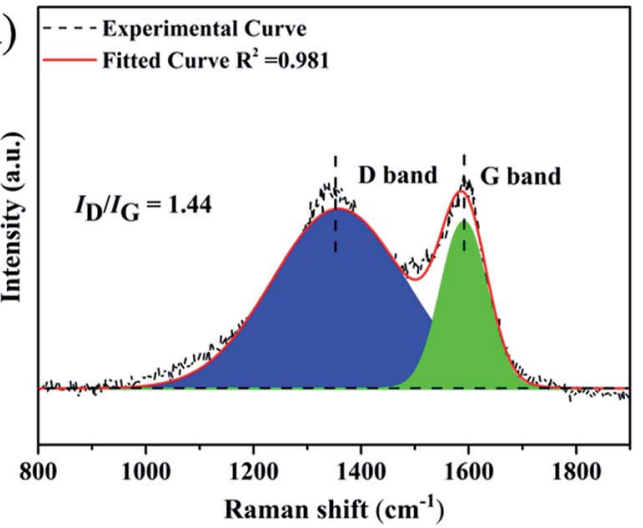

Fig. 2 XPS and Raman spectra of liquefied walnut shell-derived CNFs.

corresponds to the graphite $(\mathrm{G})$ band, which caused by the $\mathrm{E}_{2 \mathrm{~g}}$ mode of graphite. ${ }^{33}$ In order to grasp the extract information on peak areas to calculate the intensity ratio $\left(I_{\mathrm{D}} / I_{\mathrm{G}}\right)$, Gaussian fitting for the curve of D- and G-bands was used. ${ }^{34}$ Noted that the value of $I_{\mathrm{D}} / I_{\mathrm{G}}$ is 1.44 , which demonstrated that walnut shellderived PCNFs are mainly disordered carbon material. Finally, the yield of walnut shell-derived nanofibers after carbonization was determined by TGA under a nitrogen atmosphere, the TGA result showed that the CNFs contained approximately $51.7 \mathrm{wt} \%$ yield (Fig. 3).

Furthermore, the $\mathrm{N}_{2}$ adsorption/desorption isotherm was tested (Fig. 4a) and analyzed by the density functional theory model (Fig. 4b) to determine the specific surface area and the porous structure of walnut shell-derived CNFs. The isotherms of the nanofibers could be classified as type I, representing the more micropores is formed..$^{35}$ Walnut shell-derived carbon nanofibers have a BET surface are of $408 \mathrm{~m}^{2} \mathrm{~g}^{-1}$ and a microporosity ratio as high as $83 \%$ with a narrow microporous range from $0.8-1.0 \mathrm{~nm}$. All the porous structure parameters are summarized in Table 2.

The electrochemical properties of walnut shell-derived CNFs were further investigated as anode material for LIBs. Fig. 5a shows the charge/discharge curves of the walnut shell-derived carbon fibrous mats for 1st, 2nd, 3rd, 5th, 10th cycle at a current density of $100 \mathrm{~mA} \mathrm{~g}^{-1}$ between 0.1 and $3.0 \mathrm{~V}$. As seen that the walnut shell-derived CNFs electrode delivers an initial discharge and charge capacity of 341.7 and $178.5 \mathrm{~mA} \mathrm{~h} \mathrm{~g}{ }^{-1}$, respectively. The high initial irreversible capacity loss likely originates from the solid electrolyte interphase (SEI) film formation and irreversible insertion reactions of lithium-ion into the carbon structure such as the vicinity of residual heteroatoms and some voids or cavity sites. ${ }^{36,37}$ In subsequent

Table 1 XPS peak analysis of walnut shell-derived CNFs

\begin{tabular}{|c|c|c|c|c|c|c|c|}
\hline \multirow{2}{*}{ Content (\%) } & \multicolumn{5}{|l|}{ C $1 \mathrm{~s}$} & \multicolumn{2}{|l|}{$\mathrm{O} 1 \mathrm{~s}$} \\
\hline & \multicolumn{5}{|l|}{97.35} & \multicolumn{2}{|l|}{2.65} \\
\hline $\mathrm{BE}(\mathrm{eV})$ & 284.38 & 285.54 & 286.58 & 287.98 & 289.78 & 531.58 & 532.88 \\
\hline Content (\%) & 66.41 & 9.94 & 7.00 & 6.94 & 6.74 & 2.27 & 0.70 \\
\hline
\end{tabular}




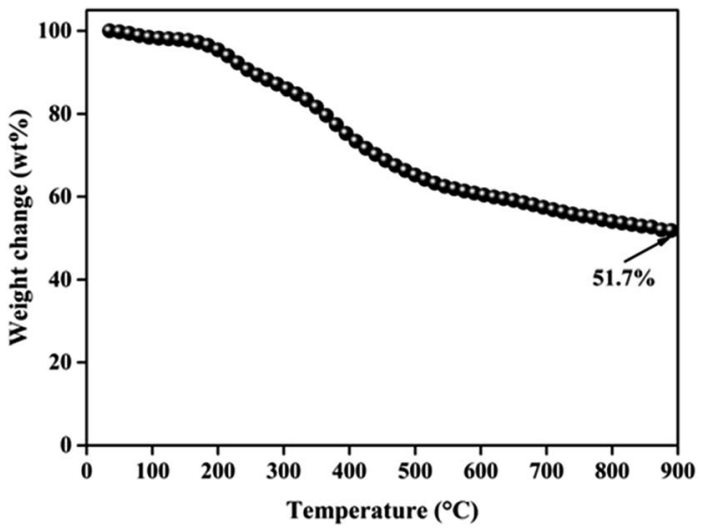

Fig. 3 TGA curve of walnut shell-derived CNFs under a nitrogen atmosphere.

cycles, the irreversible capacities reduce and reversible capacities stabilize. After 10 cycle, there is still $155 \mathrm{~mA} \mathrm{~h} \mathrm{~g}^{-1}$ reversible capacity remaining, indicating good reversibility, repeatability and good lithium-ion insertion-extraction stability of the carbon mat electrode. Besides, during the initial discharge curves, an obvious voltage plateau at $\sim 1.3 \mathrm{~V}$ suggests the rapid formation of SEI caused by the decomposition of the electrolyte, contributing to the higher irreversible capacity and lower coulombic efficiencies of the electrode $(\sim 50.4 \%$, see in Fig. 5e). ${ }^{38}$

This can be verified with the results from the CV curves of the carbon mat (Fig. 5b). In the first scan, two well-defined reduction peaks for the walnut shell-derived CNFs electrode exist distinctly, which are located at 0.31 and $0.81 \mathrm{~V}$, corresponding to the decomposition of the electrolyte on the different active surfaces of the carbon fibrous mats and the formation of SEI film, as discussed above. ${ }^{37}$ Only one small and sharp oxidation peak located at around $0.44 \mathrm{~V}$ is observed, showing the transformation of the lithium ion insertion-extraction from nanopores or nanocavities between the randomly stacked graphitelike domains, respectively. ${ }^{39}$ The following $\mathrm{CV}$ curves almost overlap after 1st cycle, indicating that the capacity decay mainly occurs in the initial cycle and the electrode exhibits a stable lithium ion insertion-extraction mechanism.
Table 2 Porous structure parameters for walnut shell-derived CNFs

\begin{tabular}{llllll}
\hline & $\begin{array}{l}S_{\mathrm{BET}}{ }^{a} \\
\left(\mathrm{~m}^{2} \mathrm{~g}^{-1}\right)\end{array}$ & $\begin{array}{l}S_{\text {micro }}{ }^{b} \\
\left(\mathrm{~m}^{2} \mathrm{~g}^{-1}\right)\end{array}$ & $\begin{array}{l}V_{\text {total }^{c}} \\
\left(\mathrm{~cm}^{3} \mathrm{~g}^{-1}\right)\end{array}$ & $\begin{array}{l}V_{\text {micro }}{ }^{d} \\
\left(\mathrm{~cm}^{3} \mathrm{~g}^{-1}\right)\end{array}$ & $\begin{array}{l}\mathrm{APW}^{e} \\
(\mathrm{~nm})\end{array}$ \\
\hline CNFs & 408 & 338 & 0.25 & 0.18 & 2.5
\end{tabular}

${ }^{a} S_{\text {BET: }}$ BET method. ${ }^{b} S_{\text {micro }}$ t-plot method. ${ }^{c} V_{\text {total }}$ : total pore volume measured at $P / P_{0}=0.99 .{ }^{d} V_{\text {micro }}$ : pore volume of micropore (pore size of $<2 \mathrm{~nm}) .{ }^{e}$ APW: adsorption average pore width ( 4 V/A by BET).

The rate capability of the walnut shell-derived CNFs electrode was investigated as shown in Fig. $5 \mathrm{c}$. The result shows that the walnut shell-derived CNFs electrode exhibits an average capacity above $200 \mathrm{~mA} \mathrm{~g}^{-1}$ in the first ten cycles at $20 \mathrm{~mA} \mathrm{~g}^{-1}$. Notably, during the initial cycle, the capacity was $345 \mathrm{~mA} \mathrm{~g}^{-1}$, much higher than other cycles, while has a lower coulombic efficiency, which originates from the SEI formation, as discussed above. Upon increasing the current density, the carbon nanofibers electrode exhibits good capacities remaining at each stage, even at a very high current density $\left(1000 \mathrm{~mA} \mathrm{~g}^{-1}\right)$, the specific capacity still remains at $120 \mathrm{~mA} \mathrm{~g}^{-1}$. When the current density was tuned back to $20 \mathrm{~mA} \mathrm{~g}^{-1}$ after cycling at different rates, the specific capacity of the carbon electrode could be almost recovered to the original value.

Fig. $5 \mathrm{~d}$ displays the cyclic stability of the walnut shell-derived CNFs electrode investigated at a current density of $100 \mathrm{~mA} \mathrm{~g}^{-1}$ up to 100 cycles, and the corresponding coulombic efficiency are shown in Fig. 5e. There was an interesting discovery that the initial capacity of the walnut shell-derived CNFs electrode showed an obvious capacity decrease from $151 \mathrm{~mA} \mathrm{~g}^{-1}$ to 123 $\mathrm{mA} \mathrm{g}^{-1}$ during the first forty cycles, which caused by SEI formed on the surface of the carbon electrode. Especially, in subsequent ten cycles, the sample exhibits good cyclic performance and a significant capacity recover to $150 \mathrm{~mA} \mathrm{~g}^{-1}$. This phenomenon could be attributed to a layer of gelatinous material (which can provide capacity) formation on the surface of the carbon electrode or SEI crack to generate a new thinner SEI film which led to the capacity increasing. ${ }^{40,41}$ During the last fifty cycles, the walnut shell-derived CNFs electrode still retained to the original capacity of $\sim 150 \mathrm{~mA} \mathrm{~g}^{-1}$ and the coulombic efficiency was still
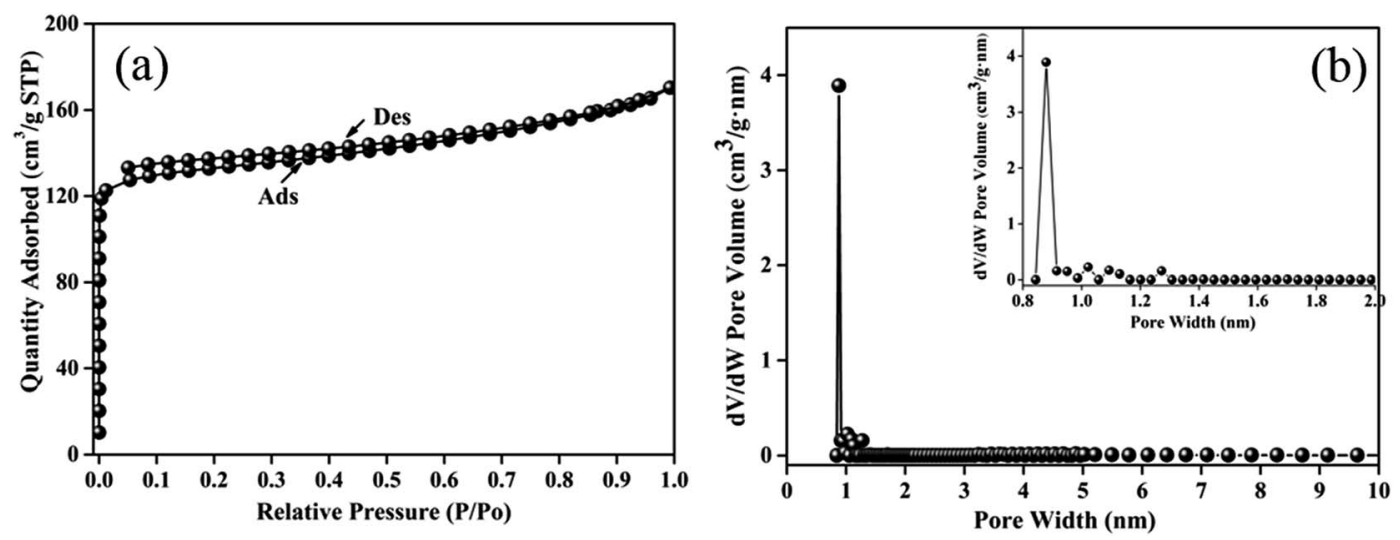

Fig. $4 \mathrm{~N}_{2}$ adsorption/desorption isotherms and pore size distribution of walnut shell-derived CNFs. 
around 99\% except for the initial columbic efficiency of $50.4 \%$. The good electrochemical stability and high degree of reversibility suggests that walnut shell-derived CNFs is relevant for electrode capacitance applications.

To better understand the electrochemical performances of the walnut shell-derived CNFs electrode, electrochemical impedance spectroscopy (EIS) study was also conducted before and after ten charge/discharge cycles at current density of 100 $\mathrm{mA} \mathrm{g}^{-1}$, shown as Fig. 5f. Before charge/discharge cycle, the impedance plot is composed of a depressed semicircle at high to medium frequency range, corresponding to the charge- transfer resistance $\left(R_{\mathrm{ct}}\right)$ at the electrolyte/electrode interface, and a sloped tail in the low-frequency region, corresponding to the Warburg impedance refers to the lithium-ion diffusion process within the solid material. ${ }^{42}$ After ten charge/discharge cycles, the curve for the walnut shell-derived CNFs electrode consists two semicircles, the first semicircle (at high frequency) can be ascribed to the SEI film resistance during cycling process and the second semicircle is due to the $R_{\mathrm{ct}}{ }^{43}$ The value of SEI film resistance and $R_{\mathrm{ct}}$ before charge/discharge cycles is $142.8 \Omega$ which increases to $173.3 \Omega$ after 10 cycles. Compared with the other carbonaceous electrodes which are made from
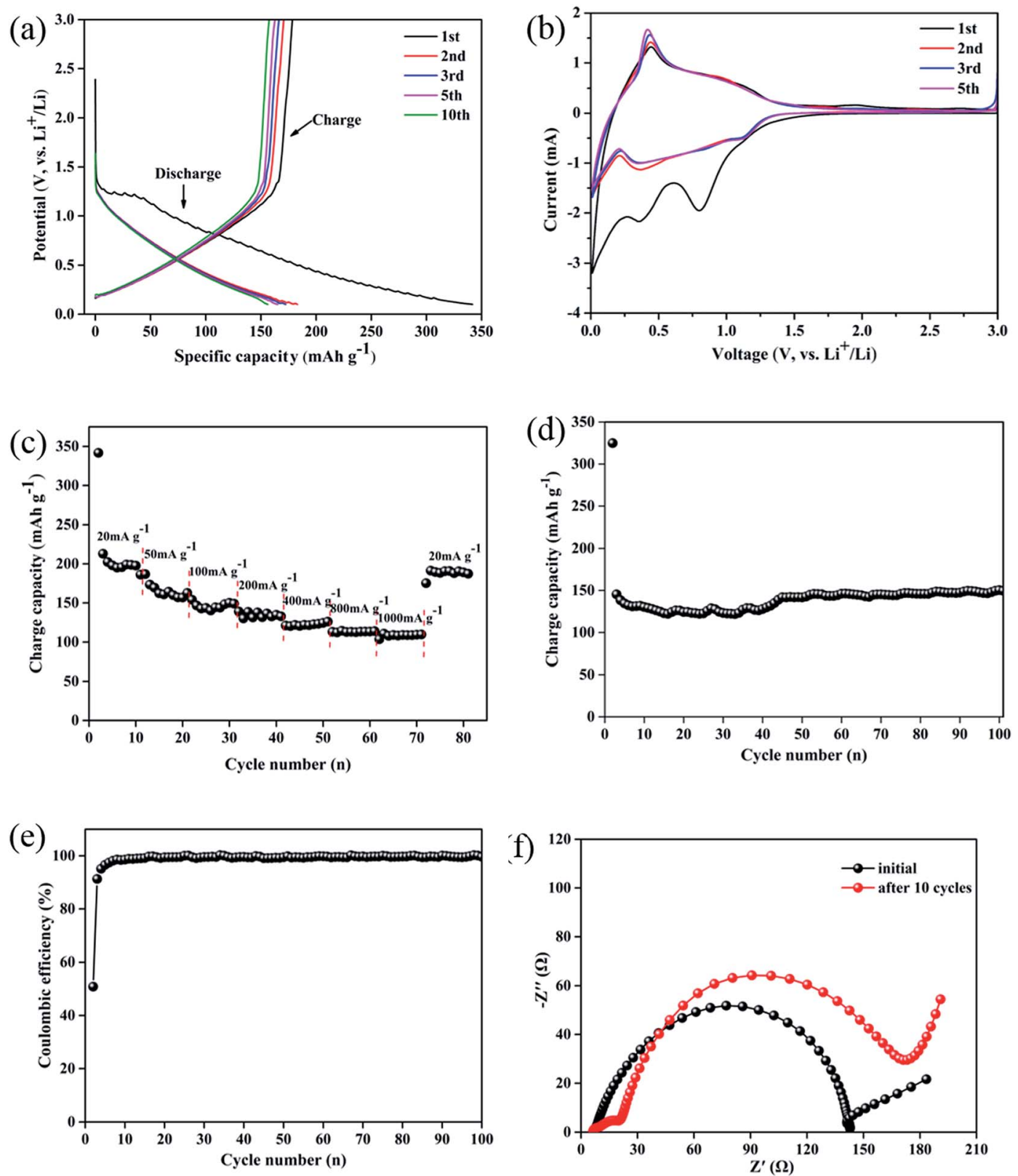

Fig. 5 Electrochemical performances of LIBs. (a) The charge/discharge curves of walnut shell-derived CNFs at current density of 100 mA g ${ }^{-1}$; (b) cyclic voltammogram of walnut shell-derived CNFs with a scan rate of $0.5 \mathrm{mV} \mathrm{s}^{-1}$; (c) charge capacities of walnut shell-derived CNFs at different current rates; (d) cyclic performance and (e) corresponding coulombic efficiency of walnut shell-derived CNFs electrodes cycled at a current density of $100 \mathrm{~mA} \mathrm{~g}^{-1}$; (f) electrochemical impedance spectroscopy (EIS) of walnut shell-derived CNFs before and after ten charge/discharge cycles at current density of $100 \mathrm{~mA} \mathrm{~g}^{-1}$ testing. 
mesoporous carbon, ${ }^{\mathbf{4 4}}$ activated carbon $^{\mathbf{4 5}}$ and porous carbon, ${ }^{\mathbf{1 0}}$ the walnut shell-derived CNFs electrode is much smaller. The lower surface charge-transfer resistance of the walnut shellderived CNFs electrode could be attributed to the favorable charge- and lithium-ion - transfer processes within the nanofiber webs, implying its good electrochemical performance.

\section{Conclusion}

In the present work, walnut shell-derived CNF mats with mechanical flexibility were obtained through electrospinning of LPF/PVA hybrid solution, followed by one-step carbonization process. Due to the characteristics of abundant micropore structure $\left(\sim 338 \mathrm{~m}^{2} \mathrm{~g}^{-1}\right)$, high specific surface area $\left(\sim 408 \mathrm{~m}^{2}\right.$ $\left.\mathrm{g}^{-1}\right)$, and much thinner diameter $(\sim 175 \mathrm{~nm})$, the walnut shellderived CNFs mats were studied as electrode materials for lithium ion batteries without addition of any conductive agent or binder. As a consequence, the carbon mats showed high performance, exhibiting a reversible charge capacity of about $150 \mathrm{~mA} \mathrm{~h} \mathrm{~g}^{-1}$ and initial efficiency of $50.4 \%$ at a current density of $100 \mathrm{~mA} \mathrm{~g}^{-1}$ with good rate capability $\left(120 \mathrm{~mA} \mathrm{~h} \mathrm{~g}^{-1}\right.$ at 1000 $\mathrm{mA} \mathrm{g}^{-1}$ ), and excellent cycling stability (150 $\mathrm{mA} \mathrm{h} \mathrm{g}^{-1}$ over 100 cycles at $100 \mathrm{~mA} \mathrm{~g}^{-1}$ ). The excellent performance, combined with inexpensive biomass, convenient fabrication technique and economical synthesis method, make walnut shell-derived CNFs to be sustainable electrode material for lithium ion batteries.

\section{Acknowledgements}

The work was supported by the Key Project of Yunnan Provincial Science Foundation (No. 2014FA034), and the National natural Science Foundation of China (No. 31670599 and No. 31160147).

\section{Notes and references}

1 Y. M. Sun, N. Liu and Y. Cui, Nat. Energy, 2016, 1, 16071.

2 N. Liu, Z. D. Lu, J. Zhao, M. T. McDowell, H. W. Lee, W. T. Zhao and Y. Cui, Nat. Nanotechnol., 2014, 9, 187.

3 B. Scrosati and J. Garche, J. Power Sources, 2010, 195, 2419. 4 J. M. Tarascon, Philos. Trans. R. Soc., A, 2010, 368, 3227.

5 M. E. Spahr, D. Goers, A. Leone, S. Stallone and E. Grivei, J. Power Sources, 2011, 196, 3404.

6 H. B. Lin, W. Z. Huang, H. B. Rong, J. N. Hu, S. W. Mai, L. D. Xing, M. Q. Xu, X. P. Li and W. S. Li, J. Power Sources, 2015, 287, 276.

7 C. Kang, M. Patel, B. Rangasamy, K. N. Jung, C. L. Xia, S. Shi and W. Choi, J. Power Sources, 2015, 299, 465.

8 K. Tang, R. J. White, X. K. Mu, M. M. Titirici, P. A. Aken and J. Maier, ChemSusChem, 2012, 5, 400.

9 H. Bi, J. Chen, W. Zhao, S. R. Sun, Y. F. Tang, T. Q. Lin, F. Q. Huang, X. D. Zhou, X. M. Xie and M. H. Jiang, $R S C$ Adv., 2012, 3, 8454.

10 L. W. Ji and X. W. Zhang, Nanotechnology, 2015, 20, 155705.

11 J. Li, R. Klöpsch, S. Nowak, M. Kunze, M. Winter and S. Passerini, J. Power Sources, 2011, 196, 7687.
12 S. X. Wang, L. P. Yang, L. P. Stubbs, X. Li and C. B. He, ACS Appl. Mater. Interfaces, 2013, 5, 12275.

13 L. L. Chai, Q. T. Qu, L. F. Zhang, M. Shen, L. Zhang and H. H. Zheng, Electrochim. Acta, 2013, 105, 378.

14 G. T. K. Fey, Y. Y. Lin, K. P. Huang, Y. C. Li, T. P. Kumar, Y. D. Cho and H. M. Kao, Adv. Mater. Res., 2012, 415, 1572.

15 L. Wang, D. Wang, Z. H. Dong, F. X. Zhang and J. Jin, Small, 2014, 10, 998.

16 H. G. Wang, S. Yuan, D. L. Ma, X. B. Zhang and J. M. Yan, Energy Environ. Sci., 2015, 8, 1660.

17 V. Aravindan, J. Sundaramurthy, P. S. Kumar, Y. S. Lee, S. Ramakrishna and S. Madhavi, Chem. Commun., 2015, 51, 2225.

18 M. J. Laudenslager, R. H. Scheffler and W. M. Sigmund, Pure Appl. Chem., 2010, 82, 2137.

19 W. E. Tenhaeff, O. Rios, K. More and M. A. McGuire, Adv. Funct. Mater., 2014, 24, 86.

20 W. L. Zhang, J. Yin, Z. Q. Lin, H. B. Lin, H. Y. Lu, Y. Wang and W. M. Huang, Electrochim. Acta, 2015, 176, 1136.

21 H. R. Lu, A. Cornell, F. Alvarado, M. Behm, S. Leijonmarck, J. B. Li, P. Tomani and G. Lindbergh, Materials, 2016, 9, 127. 22 E. Frank, L. M. Steudle, D. Ingildeev, J. M. Spörl and M. R. Buchmeiser, Angew. Chem., Int. Ed., 2014, 53, 5262.

23 S. Laurichesse and L. Avérous, Prog. Polym. Sci., 2014, 39, 1266.

24 M. Lallave, J. Bedia, R. Ruiz-Rosas, J. Rodríguez-Mirasol, T. Cordero, J. C. Otero, M. Marquez, A. Barrero and I. G. Loscertales, Adv. Mater., 2007, 23, 4292.

25 V. Poursorkhabi, A. K. Mohanty and M. Misra, J. Appl. Polym. Sci., 2015, 1322.

26 S. C. Wang, Y. Li, H. X. Xiang, Z. Zhou, T. K. Chang and M. F. Zhu, Compos. Sci. Technol., 2015, 119, 20.

27 X. Y. You, K. Koda, T. Yamada and Y. Uraki, Holzforschung, 2015, 69, 1097.

28 C. Ma, Y. Song, J. L. Shi, D. Q. Zhang, M. Zhong, Q. G. Guo and L. Liu, Mater. Lett., 2012, 76, 211.

29 C. Lai, Z. Zhou, L. Zhang, X. Wang, Q. Zhou, Y. Zhao, Y. Wang, X. F. Wu, Z. Zhu and H. Fong, J. Power Sources, 2014, 247, 134.

30 Y. Huang and G. Zhao, Holzforschung, 2016, 70, 195.

31 G. Milczarek, A. Ciszewski and I. Stepniak, J. Power Sources, 2011, 196, 7882.

32 Y. Huang, L. Peng, Y. Liu, G. Zhao, J. Y. Chen and G. Yu, ACS Appl. Mater. Interfaces, 2016, 8, 15205.

33 Y. X. Huang, E. Ma and G. J. Zhao, RSC Adv., 2015, 5, 70287. 34 S. X. Hu, S. L. Zhang, N. Pan and Y. L. Hsieh, J. Power Sources, 2014, 270, 106.

35 M. X. Wang, Z. H. Huang, T. Shimohara, F. Kang and K. Liang, Chem. Eng. J., 2011, 170, 505.

36 J. Yao, G. X. Wang, J. H. Ahn, H. K. Liu and S. X. Dou, J. Power Sources, 2003, 114, 292.

37 Y. L. Cao, L. F. Xiao, M. L. Sushko, W. Wang, B. Schwenzer, J. Xiao, Z. Nie, L. V. Laxmikant, Z. G. Yang and J. Liu, Nano Lett., 2012, 12, 3783.

38 P. Guo, H. H. Song, X. H. Chen, L. L. Ma, G. H. Wang and F. Wang, Anal. Chim. Acta, 2011, 688, 146. 
39 R. Alcántara, P. Lavela, G. F. Ortiz and J. L. Tirado, Electrochem. Solid-State Lett., 2005, 8, A222.

40 V. A. Agubra, L. Zuniga, D. Flores, J. Villareal and M. Alcoutlabi, Electrochim. Acta, 2016, 192, 529.

41 H. L. Fei, Z. W. Peng, L. Li, Y. Yang, W. Lu, E. L. Samuel, X. Fan and J. M. Tour, Nano Res., 2014, 7, 502.

42 Z. Ma, Z. Li, K. Hu, D. Liu, J. Huo and S. Wang, J. Power Sources, 2016, 325, 71.
43 Y. Li, L. B. Kong, M. C. Liu, W. B. Zhang and L. Kang, J. Energy Chem., 2016, 1, DOI: 10.1016/j.jechem.2016.11.017.

44 H. Q. Wang, Z. B. Zhao, M. Chen, N. Xiao, B. B. Li and J. S. Qiu, New Carbon Mater., 2014, 29, 280.

45 L. W. Ji and X. W. Zhang, Electrochem. Commun., 2009, 11, 684. 